\title{
Prevalence of Astigmatism and Keratoconus in Egyptian Patients Evaluated by Schleimpflug Tomography: A Retrospective Cohort Study \\ Cherine F. Osman ${ }^{1}$, Heba M. Fouad ${ }^{2}$ \\ ${ }^{1}$ Ophthalmic Diagnostic and Laser Unit (ODLU), Kasr El Einy, Cairo University \\ ,$^{2}$ Ophthalmology Department, Faculty of Medicine, Cairo University, Egypt. \\ *Corresponding author: Heba M. Fouad, MD, Ophthalmology Department, \\ Kasr El-Ainy Hospital, Elsaraya Street, Manial, Cairo, Egypt 11451, Phone: (210) 0512-9360; E-mail: heba146@cu.edu.eg
}

\begin{abstract}
Background: Scheimpflug camera uses various indices such as corneal thickness, detection of early and subclinical cases of keratoconus is challenging for the most refractive surgeon. However, corneal tomographic imaging is of great value in detecting such early changes.

Purpose: To assess the pattern of refractive conditions implying corneal astigmatism, and KC, in an Egyptian population attending a major referral diagnostic eye center, ODLU, as assessed by Schleimpflug Imaging.

Study Design: A retrospective, non-randomized, single-center, observational study.

Patients and Methods: 501 recorded files for patients who were referred to ODLU for corneal tomography assessed by Scheimpflug imaging were retrieved by the serial selection, from January 2014 to June 2016

Results: 501 eyes, of 276 patients were analyzed, 50.7\% males and $49.3 \%$ females, ranged from 5 to 80 years old, number of normal corneas was 39 eyes (7.8\%), astigmatism 0.5D-1.5D was 120 eyes (24\%), astigmatism $>1.5 \mathrm{D}$ : 342 eyes (68.3\%). The number of trauma/operated corneas( keratoplasty or LASIK) was 77 eyes(15.4\%). The number of eyes with KC was 144 eyes $(28.74 \%)$, The KC suspect corneas were 32 eyes $(6.77 \%)$

Conclusion: The largest number of patients who were referred for corneal tomography had astigmatism more than 1.5 D, the number of keratoconus suspects was higher in females in the 20 to 40 years age group, however, the severity of keratoconus was more in males at the same age group.

Keywords; Astigmatism, Keratoconus, Corneal refractive conditions, Schleimpflug Imaging, Corneal tomography, Corneal topography, Pentacam. Egyptian Population.
\end{abstract}

\section{INTRODUCTION}

Astigmatism is a common refractive error which is a common cause of visual impairment worldwide. However, it can be treated ${ }^{(\mathbf{1})}$. Uncorrected refractive errors have been associated with loss of independence and reduced quality of life ${ }^{(2)}$.

Keratoconus (KC) is a chronic, bilateral, noninflammatory disorder characterized by progressive steepening, thinning, irregular astigmatism and apical scarring of the cornea. ${ }^{(2,3)}$. New computer-based technologies and imaging methods have increased the ability to diagnose $\mathrm{KC}$ and determine the incidence of astigmatism and $\mathrm{KC}$ in different age groups.

The incidence of $\mathrm{KC}$ varies depending on factors such as ethnicity and the criteria used to establish the diagnosis. Most estimates place the incidence in the general population between 50 and 230 per 100,000, though rates vary greatly in different geographic regions ${ }^{(4)}$. Screening for clinical KC is not difficult. However, detection of the ectasia is difficult at the preclinical stages. The identification of corneas at higher risk represents a major challenge for most refractive surgeons ${ }^{(5)}$.

The Scheimpflug camera uses various indices derived from tomographic thickness evaluation parameters, such as the corneal thickness spatial profile, the percentage of thickness increase and utilizes anterior and posterior elevation data, and pachymetric data to screen for ectatic changes ${ }^{(6)}$.

\section{AIM OF THE WORK}

To determine the pattern of refractive conditions implying corneal astigmatism, and $\mathrm{KC}$, in an Egyptian population attending a major referral diagnostic eye center, ODLU, as assessed by Scheimpflug imaging.

\section{PATIENTS AND METHODS}

A total of 501 recorded files were retrieved by the serial selection, to generate a sample of the population, representative of the study. From January 2014 to June 2016, according to the serial numbers, were collected in excel sheets, retrospectively from the Scheimpflug imaging (Sirius system), for corneal tomography.

- Inclusion criteria: All patients who were referred to ODLU, to perform Scheimpflug imaging examination.

- Exclusion criteria: Patients referred to perform Scheimpflug imaging examination, for Meibomian assessment.

Scheimpflug imaging data and eyes were collected grouped and classified as follows:

According to astigmatism shape;

- With the rule astigmatism (vertical bow tie)

- Against the rule astigmatism (horizontal bow tie)

According to Astigmatism grades (our Unit classification, according to the Egyptian population); 
- Astigmatism $<0.5 \mathrm{D}=\mathrm{N}$ (Normal)

- Astigmatism 0.5D-1.5D= A (mild Astigmatism)

- Astigmatism $>1.5 \mathrm{D}=\mathrm{AA}$ (Astigmatism)

According to $\mathrm{KC}$ presence;

- $\mathrm{KC}$ suspects

- Mild $\mathrm{KC}=$ average $\mathrm{K}<48 \mathrm{D}$

- Moderate $\mathrm{KC}=$ average $\mathrm{K}<48-54 \mathrm{D}$

- Severe $\mathrm{KC}=$ average $\mathrm{K}>54 \mathrm{D}$ (according to Kanski classification of $\mathrm{KC}$ ) (3).

- Others: Trauma/Operated (LASIK/keratoplasty) eyes

Then the pattern of all groups of eyes was calculated and statistical analysis was performed and tabulated.

\section{Statistical analysis}

Statistical analysis will be done by IBM SPSS v20.0 statistical software (IBM Corporation, New York, USA). Descriptive statistics will be calculated and the data will be summarized as mean \pm standard deviation $( \pm \mathrm{SD})$, median and range, or frequencies (number of cases) and percentages when appropriate. For assessing the association between categorical data, Chi-square $\left(\chi^{2}\right)$ test will be performed. Fisher's exact test will be alternatively used when indicated. One way ANOVA will be used to study the association between categorical and numerical data if present. The results will be considered statistically significant with a $\mathrm{P}$-value $\leq 0.05$.

\section{RESULTS}

501 eyes, of 276 patients, revealed the following;

\section{I- Demographic results}

The total number of male/female patient's eyes was 254,247 respectively $(50.7 \%, 49.3 \%)$. Their age ranged between 5 years to 80 years with a mean of 28 years and was divided into four groups:

- Group 1: $5-<20$ years
- Group 2: 20 - < 40 years (The majority of the patients belonged to this age group)

- Group 3: $40-<60$ years

- Group 4: 60 - $<80$ years

- 251 Eyes were right and 250 eyes were left.

Table (1): Demographic results.

\begin{tabular}{|c|c|c|c|}
\hline Group & Number & Age (Y) & Percent (\%) \\
\hline 1 & 135 & $5-<20$ & 26.9 \\
\hline 2 & 288 & $20-<40$ & 57.5 \\
\hline 3 & 68 & $40-<60$ & 13.6 \\
\hline 4 & 10 & $60-<80$ & 2 \\
\hline
\end{tabular}

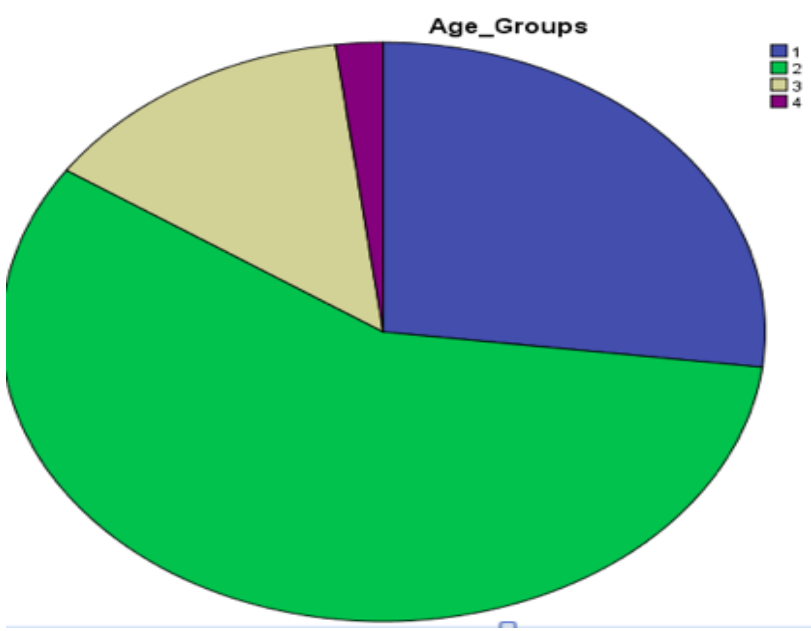

Figure (1): Age groups.

\section{II- Astigmatism results;}

- Number of normal corneas (Astigmatism $<0.5 \mathrm{D}): 39$ eyes $(7.8 \%)$

- Number of astigmatism 0.5D-1.5D: 120 eyes $(24 \%)$

- Number of astigmatism >1.5D: 342 eyes $(68.3 \%)$

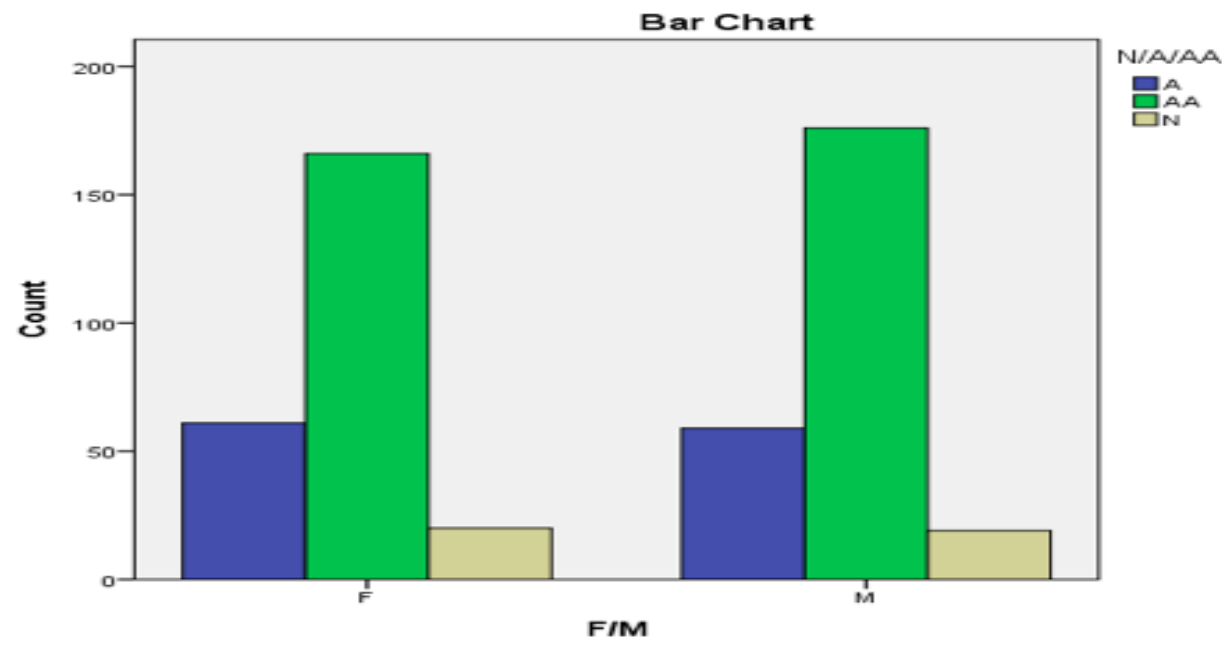

Figure (2): Prevalence of astigmatism. 
III- Trauma/LASIK/keratoplasty (operated corneas) results;

-The percentage of trauma/operated corneas( keratoplasty or LASIK): 77 eyes $=15.4 \%$.

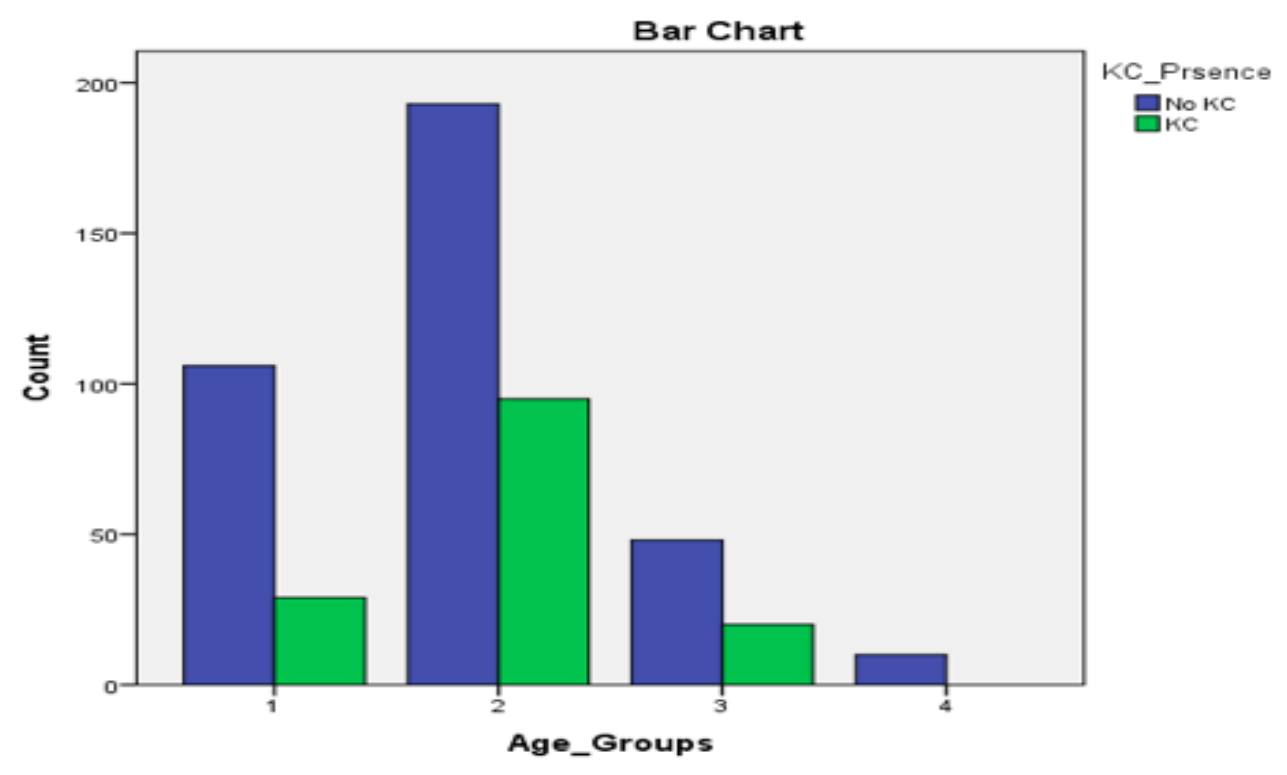

Figure (3): Prevalence of Keratoconus.

\section{IV- Keratoconus results;}

-The number of eyes with $\mathrm{KC}$ was 144 eyes $=28.74 \%$

-The $\mathrm{KC}$ suspect corneas were 32 eyes ( 21 females, 13 males $)=6.77 \%$

$2^{\text {nd }}$ age group has most of the $\mathrm{KC}$ eyes.

\section{KC characteristics;}

1- Average $K$

The highest $\mathrm{K}$ readings were among the second age group that had the highest number of keratoconus cases.

\section{2- Apex thickness}

The more steeper the cornea, the thinner the apex.

\section{3- Thinnest cornea.}

The steepest thinning of the apex occurred between age groups 2 and 3 .

The more advanced the $\mathrm{KC}$ grading, the thinner the thinnest point.

The steepest change in the apex and the thinnest point occurred between the moderate and severe $\mathrm{KC}$, and between the $2^{\text {nd }}$ and $3^{\text {rd }}$ age groups.

4- Astigmatism. The steepest change in astigmatism occurred between moderate and severe KC.

The higher the K readings, the higher astigmatism.

\section{5- Astigmatism angle.}

In mild and moderate $\mathrm{KC}$, the angle is oblique, as it gets severe, it became more towards 90 degrees.

The more advanced the Keratoconus grading, the more the average astigmatic angle, from slightly oblique to vertical 90 degrees.

-The total percentage of $\mathrm{KC}$ cases (mild/mod/severe) 144 (28.8\%)

-The female and male numbers of all $\mathrm{KC}$ case's eyes are 77 and 62 respectively.

-The number of $\mathrm{KC}$ suspect patients was 32 eyes $(6.77 \%)$ 


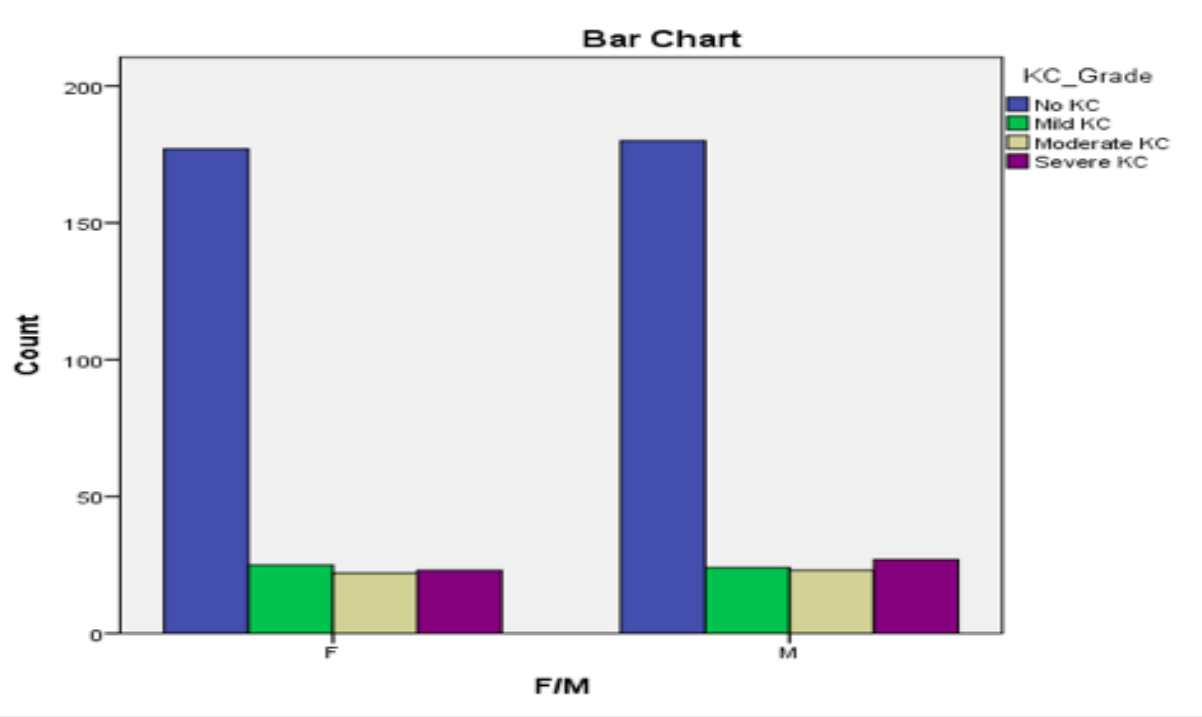

Figure 4: Keratoconus grades.

\section{DISCUSSION}

In Cairo ODLU, our study showed that the prevalence of $\mathrm{KC}$, is more in females than males, in patients performing Scheimpflug imaging, However, Males develop more advanced KC (severe) than females, however, the difference is not statistically significant.

Serdarogullari et al. (4) study, in Turkey, included 128 eyes only and showed that the prevalence of $\mathrm{KC}$ eyes in the eyes with astigmatism $>2$ Diopters was 6\%.

Our study included more number of eyes, (501 eyes), and the percentage of $\mathrm{KC}$ eyes in cases having astigmatism $>1.5 \mathrm{D}$, was almost $40 \%$ which is far more than the previous study.

Sanfilippo et al. (5) studied the association between refractive astigmatism and age in the Australian population, and they observed most changes occurring after 50 years of age, unlike the current study in Cairo, which revealed a younger age group.

Mohindra and Nagaraj's ${ }^{(6)}$ study, compared astigmatism in children of two Indian cities and discovered a statistically significant difference, suggesting genetic and environmental causes.

Rodrigez and Romero (7) concluded that hyperopia is the most refractive error and increases with aging, and the prevalence of astigmatism increases with age, and astigmatism is more frequent in females than in males. However, Pentacam was not used in this study, and $\mathrm{KC}$ cases were not involved. The current study showed different results.

Other studies as Soler $\boldsymbol{e t}$ al. ${ }^{\left({ }^{(8)}\right.}$ study in western Central Africa concluded that astigmatism was the most frequent refractive error in children. However, their study did not include any other age groups and did not include pentacam.

\section{CONCLUSION}

The largest number of patients who were referred for corneal tomography had astigmatism more than $1.5 \mathrm{D}$, the prevalence of keratoconus is more in female than male patients, especially in the age group of 20 to $\diamond 40$ years, However, the severity of keratoconus is more in males.

$>$ Financial disclosures: None

$>$ Funding: None

\section{REFERENCES}

1. Tarcy-Hornoch $K$, Ying-Lai $M$, Varma $R$ et al. (2006): Los Angeles Latino Eye Study Group Myopic Refractive error in adult Latinos: Los Angeles Latino Eye Study. Invest Ophthalmol Vis Sci., 47:1845-1852.

2. Uribe I, Swenor B, Muñoz B et al. (2011): Uncorrected refractive error in Latino population: Proyecto Ver. Ophthalmology, 118:805-811.

3. Bowling B (2015): Kanski's Clinical Ophthalmology. A systemic Approach, $8^{\text {th }}$ Edition, Chapter 6, Cornea, Corneal Ectasia, Keratoconus: Pp. 213. https://www.elsevier.com/books/kanskis-clinicalophthalmology/kanski/978-0-7020-5572-0

4. Serdarogullari H, Tetikoglu M, Karahan $\mathrm{H}$ et al. (2013): Prevalence of Keratoconus and Subclinical Keratoconus in Subjects with Astigmatism using Pentacam Derived Parameters. Journal of Ophthalmic and Vision Research, 8(3): 213-219.

5. Sanfilippo PG, Yazar S, Kears L et al. (2015): Distribution of Astigmatism as a Function of Age in an Australian population. Acta Ophthalmol., 93(5):e37785.

6. Mohindra I, Nagaraj S (1977): Astigmatism in Zuni and Navajo Indians. Am J Optom., 54(2):121-4.

7. Rodriguez NM, Romero AF (2014): The Prevalence of Refractive Conditions in Puerto Rican Adults attending an eye clinic system. Journal of Optometry, 3:161-167.

8. Soler M, Arena RG, Castro JJ et al. (2015): Prevalence of refractive errors in children in Equatorial Guinea. Opt Vis Sci., 92(1):53-8. 